\title{
Introduction to the COVID-19 Special Issue
}

\author{
Maggie Bartlett ${ }^{a}$, Stella Howden ${ }^{a}$, Alison Jones ${ }^{b},{ }^{*}$ Linda Martindale $^{a}$ \\ a: University of Dundee, Scotland, United Kingdom; b: Kingston University, United Kingdom
}

\begin{abstract}
A special issue exploring innovations and experiences in practice-based learning during the pandemic will be published over the next two editions of the International Journal of Practice-based Learning in Health and Social Care. Focusing on practice-oriented educational activities during the COVID-19 pandemic, the special issue will include research-based, evaluative and reflective articles that capture creativity, development of practice and the experiences of learners and teachers internationally.
\end{abstract}

Health and social care have been particularly affected by the COVID-19 pandemic and the impact will continue to change ways of working in health and care settings well into the future. The practice learning environment has seen rapid and widespread adaptation and change with many anecdotal examples of innovative and ground-breaking practice. The next two editions of the International Journal of Practicebased Learning in Health and Social Care will comprise a special issue exploring innovations and experiences in practice-based learning during the pandemic. Focusing on practice-oriented educational activities during the COVID-19 pandemic, the special issue will include research-based, evaluative and reflective articles that capture creativity, development of practice and the experiences of learners and teachers from a range of disciplines and countries.

The main themes for the special issue are:

- $\quad$ Policy perspectives on practice-based learning during the pandemic, including work between health and care organisations, government and higher education

- Novel and innovative approaches to practice-based learning that could help to inform future practice

- $\quad$ Student and educator perspectives of practice-based learning during COVID-19, including collaborative, partnership and alternative ways of working

*Corresponding Author: Dr Linda Martindale, Reader, Nursing, School of Health Sciences, 11 Airlie Place, University of Dundee, Scotland, UK, DD1 4HJ

Email: L.Martindale@dundee.ac.uk

Journal URL: https://publications.coventry.ac.uk/index.php/pblh

Bartlett, M., Howden, S., Jones, A., \& Martindale, L. (2021). Introduction to the COVID-19 Special Issue. International Journal of Practice-based Learning in Health and Social Care, 9(1), 77-78. DOI 10.18552/ijpblhsc.v9i1.755.

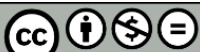

BY NC ND (C) 2021 Maggie Bartlett, Stella Howden, Alison Jones, and Linda Martindale. This Open Access article is distributed under the terms of the Creative Commons Attribution Attribution-Non-Commercial No Derivatives 4.0 International License (https://creativecommons.org/licenses/by-nc-nd/4.0/ ), which permits unrestricted non-commercial use, distribution, and reproduction in any medium, provided the original work is properly cited and is unaltered. 
The need to publish the special issue in two parts reflects the great interest and the amount of rapid innovation that there has been in this area since the start of the pandemic. The articles come from a wide range of health professions, which demonstrates how the need for change has impacted across the professions. The articles showcase creative responses and solutions to the immediate, complex issues that faced students, educators and practice partners as COVID-19 struck. Reflecting the international remit of the journal, the articles highlight responses from around the world that give insight to local experiences and issues as well as having wider relevance and applicability.

There are three development areas for practice-based learning that are highlighted across the special issue. Many of the articles explore the implementation of virtual and simulated placements in a range of settings. This includes perspectives of students, educators and other stakeholders in practice settings, which offers a rich and varied exploration of this changing area of practice. Collaboration and joint working also underpins the work discussed in many of the articles, reflecting the ways in which students, educators and clinical or practice teams worked co-operatively under pressure, to maintain practice learning, uphold the quality of education and ensure the best possible experience for students. A third area of interest is the use of national approaches, demonstrating how COVID-19 initiated new ways of thinking and working across organisations and at national level, to enable practice learning to continue.

As innovations and new practices in relation to practice-based learning look set to become mainstream in the wake of COVID-19, the special issue presents a unique set of insights and evidence that will help to inform future developments in practice learning. The topics and issues covered will be relevant to anyone interested in practice learning in health and social care. They reflect the spectrum of experiences and activities across disciplines and diverse geographical and health and care settings, and celebrate the creativity of those involved in practice-based learning. 